\title{
A Study of Outcomes Following Cochlear Implantation in Children under Adip Scheme-an Indian Experience
}

\author{
Rohit Mehrotra ${ }^{1 *}$, Anubhaw ${ }^{2}$, Pankaj Srivastav ${ }^{3}$ and Rudresh Sharma ${ }^{4}$ \\ ${ }^{1}$ Professor of ENT, Mehrotra ENT Hospital, UP, India \\ ${ }^{2,3}$ Consultant, Mehrotra ENT Hospital, UP, India \\ ${ }^{4}$ Audiologist, Mehrotra ENT Hospital, UP, India
}

*Corresponding author: Rohit Mehrotra, Mehrotra ENT Hospital, Ashok Nagar,

Kanpur, UP, India.

Received Date: May 13, 2020

Published Date: June 10, 2020

\begin{abstract}
Introduction: This retrospective study is based on assessment of outcome of cochlear implantation at Late Dr. Shiv Nath Mehrotra Charitable ENT foundation between 2016 to 2019 under ADIP(assistance to disable persons) scheme by taking into account various scoring systems like category of auditory performance (CAP), Speech intelligibility rating (SIR) and Glasgow children benefit inventory (GCBI).

Materials and methods: 300 children who were implanted between July 2016-March 2019 at Late. Dr. Shiv Nath Mehrotra Charitable ENT Foundation were included in the study. The results were analyzed using the above scoring system to assess the performance level and quality of life of each implanted children taking into consideration practical issues in Indian set up.

Results: $90 \%$ of total children implanted showed significant improved hearing, $80 \%$ with significant speech benefit and $90 \%$ with improved quality of life.

Conclusion: Outcome in terms of quality of life, auditory perception and rehabilitation was very good. The ADIP (assistance to disabled persons) scheme of central government has been a blessings for lower socio economic status children. Considerable improvement in hearing, speech and overall quality of life in almost $80 \%$ of children.
\end{abstract}

Keywords: Cochlear implantation; CAP score; SIR score; GCBI index; ADIP Scheme

\section{Introduction}

Over the last few years cochlear implantation has become the important treatment modality for children with severe to profound sensory neural hearing loss [1-4]. Inspite of dramatic improvement in cochlear implantation, various other factors decide the final result and outcome of implantation [5]. Variables affecting outcome of implant [6,7] are duration of disease, etiology of disease, age at onset of deafness, pre implant hearing aid use, communication mode, age at implantation [4], type of speech processor, duration of implant usage, family support and financial status, expertise provided, facilities for rehabilitation.
Problems unique to Indian scenarios of multi lingual society is of language barrier for rehabilitation. Well-equipped audiology unit with expertise team of audiologist are the basics for rehabilitation. Access to good schools for hearing challenged is the future way for good rehabilitation. Uniform rehabilitation in their mother tongue with active child's parent participation are essentials for auditory verbal rehabilitation [8].

Developing habilitation methods in various regional languages is a daunting tasks for diverse Indian culture. Yet cochlear implantation program has grown exponentially. 
The cochlear implantation program at Late Dr. Shiv Nath Mehrotra Charitable ENT Foundation, KANPUR under the ADIP scheme lays emphasis on after care and the extensive rehabilitation with a dedicated team of ENT surgeons, Audiologist, speech therapist, auditory verbal habilitationist and other staffs under one roof. The ADIP scheme (Assistance to disabled persons) was launched by Government of India under the leadership of our PM Shri Narendra Modi ji in 2014. It brought implantation and hearing to the lowest section of society who would never had the chance of hearing otherwise due to high costs. Under the ADIP scheme implant was procured by ALIMCO (Artificial Limbs Manufacturing
Corporation of India) Kanpur. ALI YAVAR JUNG institute of speech and hearing Mumbai became the nodal authority to distribute the implant.

(Table 1) [9] Scales: CAP is a global outcome measure applied to assess the auditory receptive abilities of hearing impaired children. The Shepherd Centre's revised version, based on Nottingham CI (cochlear implantation) Program, 1995.

(Table 2) $[10,11]$ SIR is a five point hierarchical scale globally used to measure the speech intelligibility of cochlear implantees.

Table 1: Revised CAP [9] (Categories of Auditory Perception).

\begin{tabular}{|c|c|}
\hline Level 0 & Unaware of environmental sounds \\
\hline Level 1 & Detects some environmental sounds \\
\hline Level 2 & Responds to some speech sounds \\
\hline Level 3 & Can identify some environmental sounds \\
\hline Level 4 & $\begin{array}{c}\text { Understands some spoken words with additional performatives e.g. } \\
\text { me the car brmm' }\end{array}$ \\
\hline Level 5 & Understands common phrases e.g. pick it up; it's bath time. \\
\hline Level 6 & Understands some spoken words without performatives e.g. give me the duck'/ 'go get the car' \\
\hline Level 7 & Responds appropriately to simple questions e.g. what is it? \\
\hline Level 8 & Understands conversations with familiar speakers \\
\hline Level 9 & Understands conversations with unfamiliar speakers \\
\hline Level 10 & Follows recorded stories \\
\hline Level 11 & Uses the telephone with familiar speakers \\
\hline Level 12 & Uses the telephone with unfamiliar speakers \\
\hline
\end{tabular}

Table 2: Speech intelligibility rating (SIR) $[10,11]$.

\begin{tabular}{|c|c|c|}
\hline Category & Criteria Before Implant & Time after implantation (Months) \\
\hline $\begin{array}{c}\text { Connected speech intelligible } \\
\text { to all }\end{array}$ & Who has little experience of a deaf person's speech. \\
\hline $\begin{array}{c}\text { Connected speech is intelligible } \\
\text { to a listener }\end{array}$ & Who concentrates \& lip-reads. \\
\hline $\begin{array}{c}\text { Connected speech is intelligible } \\
\text { to a listener }\end{array}$ & Speech is developing in single words when context \& lip reading cues are \\
\hline $\begin{array}{c}\text { Connected speech is un intelligi- } \\
\text { ble. Intelligible }\end{array}$ & 3 \\
\hline $\begin{array}{c}\text { Connected speech is unintelli- } \\
\text { gible. }\end{array}$ & Prerecognizable words in spoken language Primary mode of communica- \\
tion may be manual.
\end{tabular}

\section{GCBI (Glasgow Children Benefit Inventory)}

This inventory was administered using the interview method. It consists of four domains with twenty-four items, which comprehensively assessed emotional, physical health, learning and vitality aspects of parents of children with a cochlear implant with five response levels „much better, „a little better,' no changes", „a little worse" and "much worse". Scoring the GCBI each question has a range of response - much better score +2 , A little better score +1 , neither or nor worse scores 0 , A little worse scores -1 and much worse scores -2 Add up all scores for the 24 questions and divided by 24 and multiply by 50 . This should give the responses on a scale from -100 (greatest possible harm) and +100 (greatest possible benefit).

Q.1 Has child operation made overall life better or worse.

Q.2 Has operation affected the things child does.

Q.3 Has operation made behaviour better or worse.

Q.4 Has operation affected progress and development.

Q.5 Has operation affected how lively the child during the day. 
Q.6 Has operation affected how well child sleeps at night.

Q.7 Has operation affected enjoyment of food.

Q.8 Has operation affected how self-conscious with other people.

Q.9 Has operation affected how well child gets on with the rest of the family.

Q.10 Has operation affected the ability to spend time and have fun with friends.

Q.11 Has operation affected how embarrassed child feel with other people.

Q.12 Has operation affected how easily child gets distracted

Q.13 Has operation affected learning.

Q.14 Has operation affected the amount of time had to be off nursery, playgroup, or school?

Q.15 Has operation affected the ability to concentrate on the task?

Q.16 Has operation affected how frustrated and irritable child is

Q.17 Has operation affected how child feels about himself/ herself

Q.18 Has operation affected how happy and content child is

Q.19 Has operation affected child confidence

Q.20 Has operation affected the child self-care ability, such as washing, dressing, and using the toilet.

Q.21 Has operation affected the ability to enjoy leisure activities such as swimming, sports, and general play.

Q.22 Has operation affected how prone a child is to catch a cold and infections.

Q.23 Has operation affected how often child needs to visit a doctor.

Q.24 Has operation affected child needs for taking medication

\section{Materials and Methods}

Study was carried out at Late Dr Shiv Nath MEHROTRA Charitable ENT foundation KANPUR from July 2016 to March 2019. Out of 300 patients, 162 were male and 138 females. There were 5 Children in age group up to 1 year, 21 children in age group 1-2 year, 46 children in age group 2-3 years, 103 children in age group 3-4 years and 125 in age group 4-5 years. All patients received either digisonic or freedom cochlear implant.

Study was done by collecting data through fully completed clinical records and information regarding present performance of implantees from our team. The discussion also includes feedback from rehabilitation team about performance of each implantee, the duration at which patients attained speech abilities and reach the respective categories of CAP and SIR score and their GCBI index.

The following inclusion and exclusion criteria were applied to all the selected subjects in the study.

\section{Inclusion criteria}

a) Children with bilateral severe to profound sensori-neural hearing loss.

b) Age less than 5 years.

c) Income of parents is less than 1.5 lakh per annum.

d) Child has disability certificate.

e) Birth certificate for age proofing

f) Had hearing aid trial for minimum of 3 months

g) Psychological assessment was normal.

\section{Exclusion criteria}

a) Incomplete follow up

b) Incomplete insertion of cochlear implant assessed by intra-operative neural response telemetry

c) Explanation on account of any reason.

2 children were excluded from the study due to their death. One child died in road traffic accident and one died due to dengue fever.

\section{Evaluation protocol at Mehrotra ENT Hospital}

a. Informed written consent was taken from the parents for the study and follow-ups required during the study.

b. A detailed history and thorough physical and ENT examination was carried out.

c. The subjects then underwent pediatric examination to rule out any neurological condition, which may hamper the child postoperative performance. Prior to implantation a basic workup including hematological, chest X-ray, ECG (electrocardiogram), TORCH (toxoplasmosis, rubella, cytomegalovirus, herpes simplex, and HIV) screen (if require). The general physical condition will be evaluated by anesthetis. A specialist opinion was sought in patients with syndromic etiology of deafness. In children pre implant vaccination will be carried out.

d. Behavioral oservational audiometry, impedance, OAE (otoacoustic emissions), auditory brainstem response thresholds and auditory steady-state response was determind to evaluate the degree of hearing loss.

e. Each child was subjected to undergo a high resolution CT (computed tomography) scan and MRI (magnetic resonance imaging) scan of Temporal bones. 
f. Speech perception was also assessed by SIR score before implant

g. The child was also evaluated by a child psychologist to determine the IQ (intelligent quotient).

h. Counselling of parents was done regarding regular follow-ups and therapy/support to the child at home. They were also made to realize the realistic expectations about the cochlear implant. Also the parents were made to realize that they are integral part of our rehabilitation team which requires consistent hard work and patience.

Cochlear implantation was done and the impedance checked. Neural Response Telemetry (NRT) was done in nucleus implants and effectiveness assessed in children. Post operatively x-ray was mandatory. The switch on and speech processor tuning done at 1-2 weeks after surgery. Mapping is done at periodic intervals till a stable map is achieved. The rehabilitation program was started out based on baseline skills of child, periodical assessment of outcomes was done in terms of environmental sound speech discrimination and telephonic conversation. The recommended period for rehabilitation under ADIP scheme is 2 years. All 300 children are using the implant. There are no non users.

\section{Outcome measures}

The subjects were followed up for a maximum period of 1 year at intervals of 3 months, 6 months and 12 months after implantation. Outcome measures were followed as under

\section{-CAP SCORE}

Children were assessed prior to implantation, at 3, 6 and 12 months post implant.
-SIR

Children were assessed at 3, 6 and 12 months follow up. -GCBI

Calculated at the end of 12 months.

\section{Results}

Out of total 300 children 162 were males and 138 were females. 5 children belongs to age group less than 1 year, 21 in age group 1-2 years, 46 in 2-3 year age group, 103 in 3-4year age group and 125 in age group 4-5 years of age. 249 were Hindu and 51 Muslim. 101 were general category, 162 other backward class and 37 SC category. 110 children are of Kanpur nagar, 190 of other districts. $260(86.6 \%)$ children were operated in right side and $40(13.3 \%)$ in left side. 137(44.9\%) were implanted digisonic, 163(55.1\%) freedom device.

Wearing hearing aid early helped the children to improve auditory skills

$\bullet 11.1 \%$ children used hearing aids $<4$ months

-24.4\% children used hearing aids 4-6 months

$\bullet 10.8 \%$ children used hearing aids 6-8 months

-53.6\% children used hearing aids $>8$ months.

\section{Comparison of SIR score, GCBI and CAP score}

(Table 3) At the end of 1 year $02 \%$ have attained level 11, $04 \%$ have attained level 10, 07\% have attained level 9, 08\% have attained level 8, 18\% score level $7,21 \%$ level 6, 25\% level 5, 13\% level 4 and $2 \%$ level 3.

Table 3: CAP Score at end of 1 year.

\begin{tabular}{|c|c|}
\hline Levels & At the end of 12 Months \\
\hline 11 & $2 \%$ \\
\hline 10 & $4 \%$ \\
\hline 9 & $7 \%$ \\
\hline 8 & $8 \%$ \\
\hline 7 & $18 \%$ \\
\hline 6 & $21 \%$ \\
\hline 5 & $25 \%$ \\
\hline 4 & $13 \%$ \\
\hline 3 & $2 \%$ \\
\hline
\end{tabular}

Nearly $80 \%$ of children in age less than 3 had attained higher level of CAP (level 7,8,9,10) whereas in age group of 3-5 years only 9\% had attained highest level of 9, 8 and 7) highlighting the need for early age implantation [12]. All of these $70 \%$ of children in age group less than 3 attaining level of 7-10 were prior hearing aid users which again emphasise on better outcome with prior hearing aid users.
Few Children in age more than 3 having no prior hearing aid use had still attained a minimum level of 3 thanks to timely implant intervention and extensive rehabilitation by our dedicated team.

Even age group more than 3 showed improved results as 19\% of age more than 3 had attained level 7 and 8 which was result of hard and extensive rehab programme at our centre. 
Overall $90 \%$ of total children showed significant improvement in hearing. All of these children parents were highly dedicated and regular follow up was done. The remaining faired not so better owing to poor compliance by child parents showing less dedication stressing the need for regular follow up and high dedication (Figure 1) (Table 4).

Table 4: SIR at end of 1 year.

\begin{tabular}{|c|c|}
\hline Category of SIR & Percentage of Childern \\
\hline 5 & $16 \%$ \\
\hline 4 & $34 \%$ \\
\hline 3 & $30 \%$ \\
\hline 2 & $19 \%$ \\
\hline 1 & $1 \%$ \\
\hline
\end{tabular}

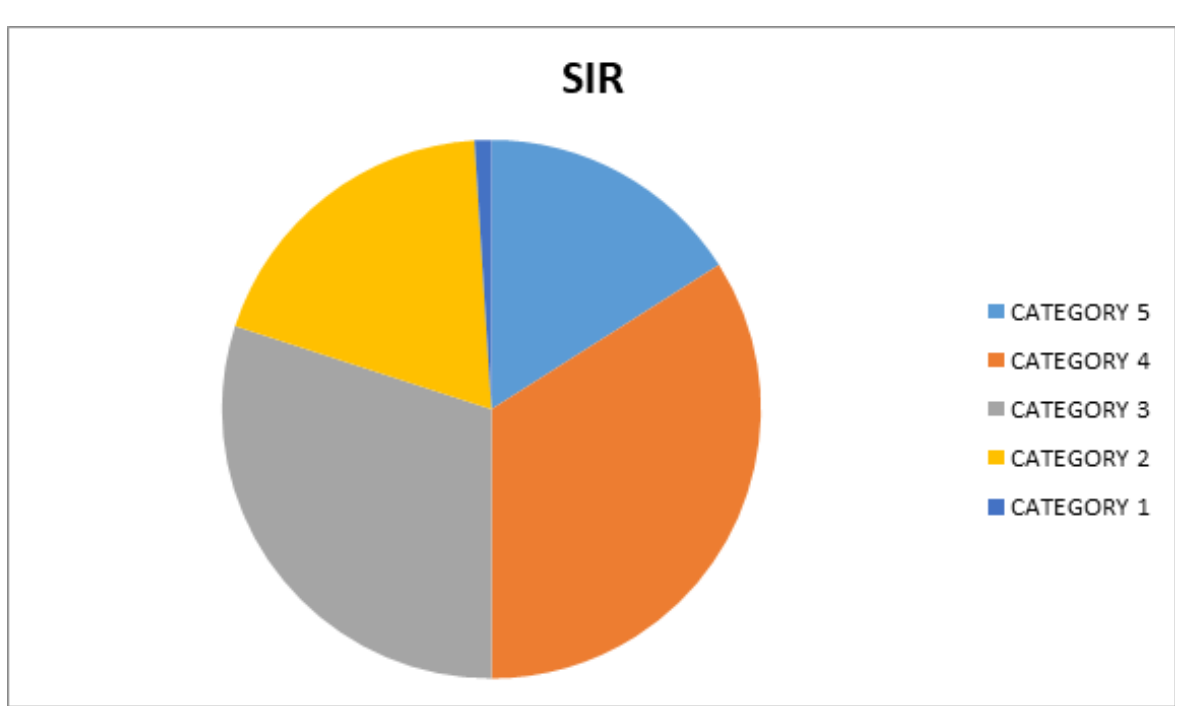

Figure 1: Showing SIR Score at the end of year.

At the end of 1 year $16 \%$ have got score of 5, 34\% have score of $4,30 \%$ score of $3,19 \%$ score of 2 and $01 \%$ score of 1 . Almost $80 \%$ children had shown significant improvement in speech at the end of 1 year after implantation. The trend showed extensive rehabilitation with regular follow up with good compliance lead to improve outcome not only in hearing but also in speech. Trends in SIR score is similar to that of CAP levels with nearly $80 \%$ children in age less than 3 years showed better score compared to group

Table 5: GCBI at end of 1 year.

\begin{tabular}{|c|c|}
\hline Index & Percentage \\
\hline $60-100$ & $64 \%$ \\
\hline $30-60$ & $26 \%$ \\
\hline $0-30$ & $10 \%$ \\
\hline
\end{tabular}

(Figure 2) One year is a relatively short follow up period for evaluation of outcome. Communication skills continue to improve for several years post implantation [11, 13] and hence present results reflect only short term outcome. However most children achieved higher scores for both CAP and SIR after one year postoperatively, probably indicating that in future they will master communication skills at higher level $[14,15]$, the results of which more than three years. The SIR score is also greater in children with prior hearing aid users and better in those who had some residual hearing left prior to implantation.

(Table 5) At the end of 1 year 64 has attained maximum benefit, $26 \%$ has attained moderate benefit and $10 \%$ has attained only mild benefit. Overall $90 \%$ showed significant improvement in quality of life. will be available further publications.

\section{Age group wise results}

(Table 6) Age group of less than 3 year showed better CAP level, better SIR and better GCBI index when compared to greater than 3 years. GCBI at end of 1 year showed maximum benefit in almost all of children less than 3 years age. 


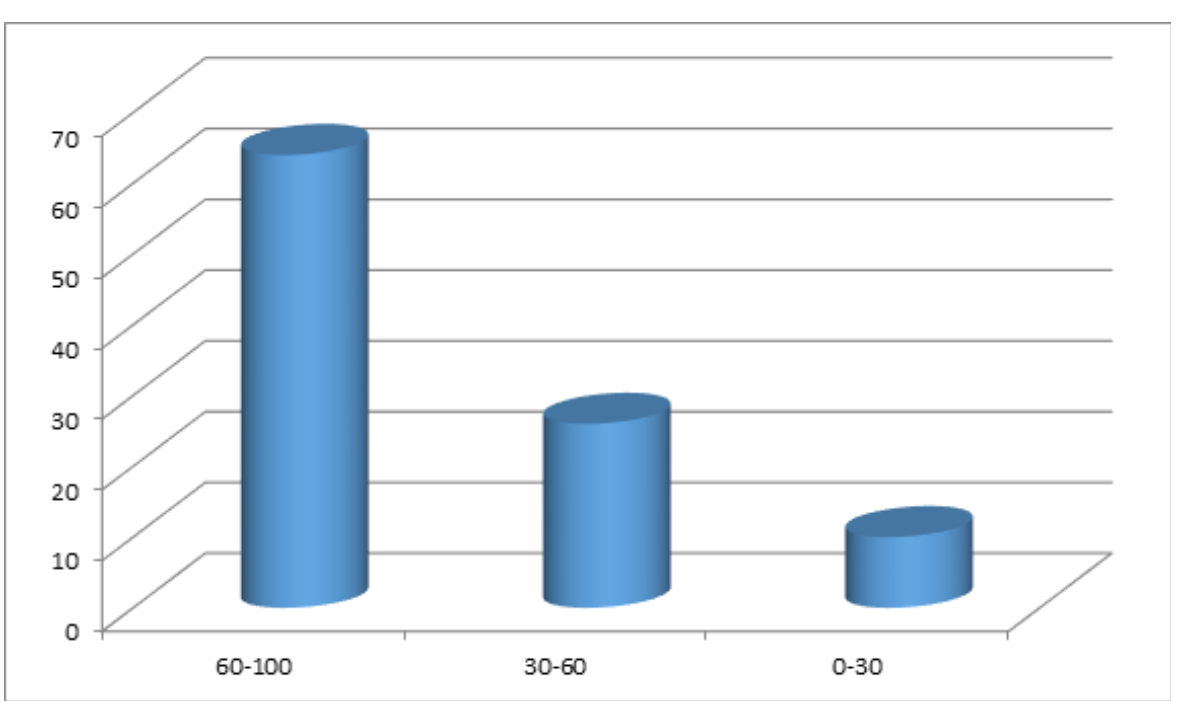

Figure 2: Showing Graph of GCBI at end of 1 year.

Table 6: Comparison of Age with Mean Cap Score.

\begin{tabular}{|c|c|c|c|}
\hline Age Group & Highter CAP Levels (9,10) & MID CAP Levels(6,7,8) & Lower CAP Levels (1-5) \\
\hline Age $<3$ YEARS & $54 \%$ & $46 \%$ & $0 \%$ \\
\hline Age $>3$ YEARS & $0 \%$ & $48 \%$ & $52 \%$ \\
\hline
\end{tabular}

\section{Follow up}

$83.30 \%$ children were regular in follow up $16.60 \%$ irregular.

\section{Complications}

1) 07 patients had facial paresis which recovered in 4-6 weeks.

2) 12 hematoma which recovered in 2 weeks.

3) 02 had discharge which recovered in 01 week.

4) 01 keloid.

7. Conclusion

1) Early age of less than 3 years or ideally less than 2 years showed better hearing, better speech and better quality of life. Spoken language performance results are best for those implanted prior to age 3 .

2) Religion plays no role.

3) Prior hearing aid users performed better in all aspects. The greater the period of hearing aid use and shorter the period of time of hearing deprivation $[4,16]$ better the outcome and easier development of spoken language.

4) Regular follow up during rehabilitation is key to improve results

5) Dedicated educated parents are as important as other factors for successful outcome.

6) As the complications were minimal, surgery was safe [17].
7) All children were using the implant. There were no non users.

8) $90 \%$ of children implanted showed significant hearing improvement at end of 1 year follow up.

9) $80 \%$ of children showed significant speech improvement at end of 1 year follow up.

10) $64 \%$ had maximum benefit in terms of quality of life, $26 \%$ moderate and $10 \%$ had mild benefit.

11) ADIP scheme has changed the life of children with lower socio economic status.

\section{Acknowledgement}

None.

\section{Conflict of Interest}

No conflicts of interest.

\section{References}

1. Beadle EAR, McKinley DJ, Nikolopoulos TP (2005) Long-term functional outcomes and academic-occupational status in implanted children after 10 to 14 years of cochlear implant use. Otol Neurotol 26:1152-1160.

2. Hehar SS, Nikolopoulos TP (2002) Surgery and functional outcomes in deaf children receiving cochlear implants before age 2 years. Arch Otolaryngol Head Neck Surg 128: 11-14.

3. NICE technology appraisal guidance TAG166 (2009) Cochlear implants for children and adults with severe to profound deafness.

4. O'Neil C, O'Donoghue GM, Archbold SM (2001) Variations in gains in auditory performance from pediatric cochlear implantation. Otol Ncurotol 23: 44-48. 
5. Colleti, Vittorio MD, Carner, Marco MD, Miorelli, et al. (2005) Cochlea implantation at under 12 months; Report on 10 Patients. Laryngoscope 115: 445-449.

6. Black J, Hickson L, Black B (2012) Defining and evaluating success in paediatric cochlear implantation-an exploratory study. Int J Pediatr Otorhinolaryngol 76: 1317-1326.

7. Driver S, Jiang D (2017) Paediatric cochlear implantation factors that affect outcomes. Eur J Paediatr Neurol 21: 104-108.

8. Tait M, Lutman ME (1997) Predictive value of measures of preverba communicative behavior in young deaf children with cochlear implants. Ear Hear 8: 472-478.

9. Archbold S, Lutman ME, Marshall DH (1995) Categories of Auditory Performance. Ann Otol Rhinol Laryngol 166: 312-314

10. Allen C, Nikolopoulos TP, Dyar D (2001) Reliability of a rating scale for measuring speech intelligibility after paediatric cochlear implantation. Otol Neurotol 22: 631-633.

11. Allen C, Nikolopoulos TP, O’Donoghue GM (1998) Speech intelligibility after cochlear implantation. Am J Otol 19: 742-746.
12. Osberger MJ (1997) Cochlear Implantation in children under 2 years, Candidacy consideration, Otolaryngol Head Neck Surg 117: 145-149.

13. Nikolopoulos TP, Archbold SM, O’Donoghue GM (1999) The development of auditory perception in children following cochlear implantation. Int J Pediatr Otorhinolaryngol 49: S189-S191.

14. Calmels MN, Saliba I, Wanna G (2004) Speech perception and speech intelligibility in children after cochlear implantation. Int J Pediatr Otorhinolaryngol 68: 347-351.

15. Inscoe J (1999) Communication outcomes after paediatric cochlear implantation. Int J Pediatr Otorhinolaryngol 47: 195-200.

16. Waltzman SB, Roland JT, Cohen NL (2002) Delayed implantation in congenitally deaf children and adults. Otol Neurotol 23: 333-340.

17. Ovesen T, Johansen LV (2009) Post-operative problems and complications in 313 consecutive cochlear implantations. J Laryngol Otol 123: 492-496. 